\title{
Explaining sex differences in chronic musculoskeletal pain in a general population
}

\author{
Hanneke A.H. Wijnhoven ${ }^{a, b}$, Henrica C.W. de Vet ${ }^{b}$ and H. Susan J. \\ Picavet $^{\text {a, }}$
}

\author{
${ }^{a}$ National Institute of Public Health and the Environment, Center for Prevention \\ and Health Services Research (PZO, pb 101), PO Box 1, 3720 BA Bilthoven, The \\ Netherlands \\ ${ }^{\mathrm{b}}$ EMGO Institute, VU University Medical Center, Van der Boechorststraat 7, 1081 \\ BT Amsterdam, The Netherlands
}

Received 29 August 2005; revised 21 March 2006; accepted 3 April 2006. Available online 22 May 2006.

Corresponding author: H. Susan J. Picavet. Tel.: +31 302743 063; fax: +31 30 2744409.

\begin{abstract}
Many studies report a female predominance in the prevalence of chronic musculoskeletal pain (CMP) but the mechanisms explaining these sex differences are poorly understood. Data from a random postal questionnaire survey in the Dutch general population were used to examine whether sex differences in the prevalences of CMP are due to sex differences in the distribution of known potential risk factors for CMP (exposure model) and/or to the different importance of risk factors for CMP (i.e. show different strength of association) in men and women (vulnerability model). In the present analyses, 909 men and 1178 women aged 25-65 were included. CMP was defined as pain lasting longer than 3 months and was assessed for 10 anatomical locations (neck, shoulder, higher back, elbow, wrist/hand, lower back, hip, knee, ankle, foot). Sex differences in CMP could not be explained by a different distribution of age, educational level, smoking status, overweight, physical activity, and pain catastrophizing. Having no paid job was associated with CMP, explaining part of the sex differences, but its role seems complex. Risk factors with a sex-specific association were: overweight (all pain locations) and older age (lower extremities) - both having only an effect among women - and pain catastrophizing (upper extremities), which was stronger associated with CMP among men than among women. In conclusion, sex differences in prevalence of CMP may partly be explained by sex differences in vulnerability to risk factors for CMP. Future research towards sex-specific identification of risk factors for CMP is warranted. Eventually this may lead to sexspecific prevention and management of CMP.
\end{abstract}

Keywords: Muscuskeletal pain; Sex; Gender; General population

\section{Introduction}

Many studies report a female predominance in the prevalence of musculoskeletal pain (MP) in both the general population (Andersson et al., 1993, Natvig et al., 1995, Urwin et al., 1998, Bergman et al., 2001 and Wijnhoven et al., in press) and the working population (de Zwart et al., 2001, Eriksen, 2003 and Guo et al., 
2004), but the underlying mechanisms explaining these sex differences are poorly understood. Explanations can roughly be divided into three categories: (1) women are, more than men, willing to report MP; (2) women are, more than men, exposed to risk factors for MP (exposure model); and (3) women are more vulnerable than men to develop MP meaning that women react in different way to risk factors for MP (vulnerability model). These differences in vulnerability may be due to differences in sex-linked biologic factors (hormones or physiology), different pain sensitivity, or differences in social or psychological factors (Punnet and Herbert, 2000, Denton et al., 2004 and Strazdins and Bammer, 2004). There is limited research on exposure and vulnerability models explaining sex differences in MP. Among white-collar government employees, sex differences in upper musculoskeletal disorders were explained by different demands that men and women face at work or at home, supporting the exposure model, while no support was found for the vulnerability model (Strazdins and Bammer, 2004). In a general population study, sex differences in health were only minimally reduced by controlling for structural, behavioral, and psychosocial forces (not supporting the exposure model), while social predictors of health differed between men and women (supporting the vulnerability model) (Denton et al., 2004).

Several risk factors for MP in various anatomical pain locations have been identified. Strongest and most consistent associations are found for occupational exposure, both physical and psychosocial (Felson et al., 2000, van der Windt et al., 2000, Miranda et al., 2001, van Tulder et al., 2002 and Palmer, 2003), and general psychosocial factors like stress, anxiety, mood/emotions, cognitive functioning and pain behavior (Miranda et al., 2001, van Tulder et al., 2002, Gran, 2003 and Palmer, 2003). In addition, pain-related fear (pain catastrophizing) and avoidance behavior appear to be an essential feature of development of a chronic problem for a substantial number of patients with MP (Vlaeyen and Linton, 2000). Weaker but positive associations are also found for obesity or overweight (Oliveria et al., 1999, Leboeuf-Yde, 2000 and Peltonen et al., 2003), smoking (Andersson et al., 1998, Leboeuf-Yde et al., 1998, Feldman et al., 1999 and Leboeuf-Yde, 1999), increasing age (de Zwart et al., 1997, Webb et al., 2003 and Guo et al., 2004), and lower educational level or lower occupational class (Leino-Arjas et al., 1998 and Guo et al., 2004). A systematic review on the association between physical activity and both low back pain and neck pain showed inconsistent but mostly no associations (Hildebrandt et al., 2000).

This paper presents data of a large-scale population-based study examining whether: (1) sex differences in the distribution of known potential risk factors for chronic MP (CMP) (older age, lower educational level, smoking status, work status, overweight, physical inactivity, and pain catastrophizing) explain sex differences in CMP (exposure model); and whether (2) risk factors for CMP have different importance (i.e. show different strength of association) in men and women (vulnerability model).

\section{Methods}

This study uses data of the 'Dutch population-based Musculoskeletal Complaints and Consequences Cohort study' ( $\mathrm{DMC}_{3}$-study). The $\mathrm{DMC}_{3}$-study is a questionnaire-based study among a sex- and age-stratified sample of noninstitutionalized Dutch inhabitants aged 25 years or older. An extensive description of the $\mathrm{DMC}_{3}$-study can be found elsewhere (Picavet and Schouten, 2003). At the baseline assessment in 1998, written questionnaires were sent by post to 8000 Dutch inhabitants. The questionnaire was completed and returned by 3664 respondents. In the questionnaire data were collected on, among other 
things, musculoskeletal pain (including anatomical pain location, duration, severity), general background characteristics, physical activity, and psychological aspects on pain (pain catastrophizing). Of the original sample 182 had moved or were deceased so the net response was $3664 /(8000-182)=47 \%$. In the present study, respondents older than 65 years were excluded because we wanted to study the effect of work status and because at older age co-morbidity plays an important role. Of the 3664 respondents of the $\mathrm{DMC}_{3}$-study, 2517 respondents were aged 25-65 years. Of these respondents, 430 respondents were excluded due to missing data, leaving 2087 respondents with complete data (909 men and 1178 women) to be included in the present study. These 2087 respondents did not differ significantly from the initial 2517 respondents (Table $1)$.

Table 1.

The Dutch population-based Musculoskeletal Complaints and Consequences Cohort study ( $\mathrm{DMC}_{3}$-study); characteristics of the study population

\begin{tabular}{|c|c|c|c|c|c|}
\hline & \multirow{2}{*}{$\begin{array}{l}\begin{array}{l}\mathrm{DMC}_{3}- \\
\text { study }^{\mathrm{a}}\end{array} \\
\begin{array}{l}n=2517 \\
(100 \%)\end{array}\end{array}$} & \multicolumn{2}{|c|}{ Present analyses $^{b}$} & & \\
\hline & & $\begin{array}{l}n=2087 \\
(82.9 \%)\end{array}$ & & & \\
\hline & & $\begin{array}{l}\text { Tot } \\
n=2087 \\
(100 \%)\end{array}$ & $\begin{array}{l}\text { Men } \\
n=909 \\
(43.6 \%)\end{array}$ & $\begin{array}{l}\text { Women } \\
n=1178 \\
(56.4 \%)\end{array}$ & \\
\hline & $\%$ & $\%$ & $\%$ & $\%$ & $p$-value ${ }^{c}$ \\
\hline Men & 42.5 & 43.6 & & & \\
\hline $25-35$ years & 21.3 & 23.1 & 21.1 & 24.5 & 0.15 \\
\hline $36-45$ years & 25.2 & 27.3 & 26.5 & 27.8 & \\
\hline $46-55$ years & 26.1 & 26.6 & 28.1 & 25.4 & \\
\hline $56-65$ years & 27.5 & 23.1 & 24.3 & 22.2 & \\
\hline Low educational level & 48.3 & 43.1 & 39.6 & 47.6 & \\
\hline Medium educational level & 27.8 & 29.7 & 30.4 & 29.1 & $<0.01$ \\
\hline High educational level & 23.9 & 26.2 & 30.0 & 23.3 & \\
\hline Paid job (versus no paid job) & 55.1 & 59.2 & 79.2 & 43.8 & $<0.01$ \\
\hline Never smoker & 32.8 & 33.1 & 22.7 & 36.6 & \\
\hline Past smoker & 35.6 & 35.8 & 37.5 & 34.5 & $<0.01$ \\
\hline Current smoker & 31.6 & 31.1 & 33.9 & 28.9 & \\
\hline BMI $\geqslant 25$ (versus BMI <25) & 41.4 & 39.4 & 46.0 & 34.3 & $<0.01$ \\
\hline
\end{tabular}




\begin{tabular}{|c|c|c|c|c|c|}
\hline & \multirow{2}{*}{$\begin{array}{l}\begin{array}{l}\mathrm{DMC}_{3-} \\
\text { study }^{\mathrm{a}}\end{array} \\
\begin{array}{l}n=2517 \\
(100 \%)\end{array}\end{array}$} & \multicolumn{2}{|c|}{ Present analyses $^{b}$} & \multirow[b]{3}{*}{$\begin{array}{l}\text { Women } \\
n=1178 \\
(56.4 \%)\end{array}$} & \\
\hline & & $\begin{array}{l}n=2087 \\
(82.9 \%)\end{array}$ & & & \\
\hline & & $\begin{array}{l}\text { Tot } \\
n=2087 \\
(100 \%)\end{array}$ & $\begin{array}{l}\text { Men } \\
n=909 \\
(43.6 \%)\end{array}$ & & \\
\hline Low physical activity (versus moderate-intensive activity) & 45.8 & 45.8 & 48.7 & 43.5 & 0.02 \\
\hline Lowest tertile pain catastrophizing & 31.2 & 31.2 & 37.5 & 26.4 & \\
\hline Middle tertile pain catastrophizing & 33.7 & 34.4 & 33.1 & 35.4 & $<0.01$ \\
\hline Highest tertile pain catastrophizing & 35.1 & 34.4 & 29.4 & 38.2 & \\
\hline Chronic neck pain & 15.6 & 15.5 & 11.0 & 18.9 & $<0.01$ \\
\hline Chronic shoulder pain & 16.8 & 16.6 & 13.5 & 19.0 & $<0.01$ \\
\hline Chronic higher back pain & 6.8 & 6.7 & 4.2 & 8.7 & $<0.01$ \\
\hline Chronic elbow pain & 6.0 & 5.9 & 5.1 & 6.6 & 0.16 \\
\hline Chronic wrist/hand pain & 9.4 & 9.5 & 6.5 & 11.9 & $<0.01$ \\
\hline Chronic lower back pain & 21.8 & 21.7 & 21.8 & 21.6 & 0.95 \\
\hline Chronic hip pain & 7.1 & 6.3 & 3.6 & 8.3 & $<0.01$ \\
\hline Chronic knee pain & 11.0 & 11.0 & 10.1 & 11.7 & 0.28 \\
\hline Chronic ankle pain & 3.4 & 3.4 & 2.8 & 3.9 & 0.19 \\
\hline Chronic foot pain & 5.0 & 4.8 & 3.6 & 5.8 & 0.03 \\
\hline Chronic pain any location & 47.3 & 45.6 & 41.4 & 48.9 & $<0.01$ \\
\hline
\end{tabular}

a Excluding those older than 65 years.

${ }^{b}$ All respondents with missing data are excluded.

${ }^{c}$ Differences between men and women are tested by $X^{2}$-tests.

Questions on musculoskeletal pain included 10 anatomical pain locations: neck, shoulder, higher part of the back, elbow, wrist/hand, lower part of the back, hip, knee, ankle, and foot. Chronic musculoskeletal pain (CMP) was defined as current pain (i.e. an episode of pain during completion of the questionnaire) which lasted longer than 3 months in the past 12 months. Background information on participants consisted of: age (categorized into $25-45 ; 45-65$ ); level of education (low = primary school; middle $=$ junior vocational education/secondary vocational education; high = vocational colleges/university); work status (paid job or no paid job); smoking status (never; past; current); and overweight $\left(\right.$ BMI $\left.>25 \mathrm{~kg} / \mathrm{m}^{2}\right)$. Physical activity was assessed using a slightly modified version of the SQUASH questionnaire (Wendel-Vos et al., 2003), which is a validated questionnaire on physical activity. Physical activity was categorized into: (1) low physical activity; and (2) moderate to high physical activity which was defined by a minimum of 30 min or more of moderate intense physical activity per day 
during one week. Pain catastrophizing was assessed using a Dutch version of the Pain Catastrophizing Scale (Sullivan et al., 1995). This is a 13-item scale in which participants are asked to indicate the degree to which they experience certain thoughts or feelings during pain on a 5-point scale, ranging from 1 (not at all) to 5 (always). An example of an item is: "If I am in pain, I am afraid the pain will get worse". A Pain Catastrophizing Scale Sum score was calculated from all items (range, 13-65). Pain catastrophizing was categorized into three groups (low, medium, and high level of pain catastrophizing) based on tertiles of scores in the total study population (Picavet et al., 2002).

\subsection{Statistical analyses}

An overall variable for presence of CMP was constructed $(1=$ CMP in any of the 10 anatomical pain locations; $0=$ no CMP). In order to calculate prevalence ratios instead of odds ratios, Cox regression was used to assess the association between female sex (independent variable) and prevalence of CMP (dependent variable) for all 10 anatomical pain locations separately and the overall variable of CMP. A constant risk period was assigned to all respondents in the study, so that the estimated hazard ratio equals the prevalence ratio (PR) (Barros and Hirakata, 2003). In order to examine to what extent the relation between sex and CMP is explained by a sex-related distribution of other potential risk factors for CMP (age (four categories), level of education, work status, smoking status, overweight, physical activity, and pain catastrophizing), these other risk factors were added to each Cox regression model both individually and simultaneously. A large change between unadjusted and adjusted PR values points to different exposures to the specific risk factors for men and women. The percentage change in PR was calculated: $[\%$ change $=(P R($ crude $)-P R($ adjusted $)) / P R($ crude $) \times 100] . A$ change of $10 \%$ or more was considered as relevant. Finally, sex-stratified multivariate Cox regression models were constructed with all potential risk factors of CMP as the independent variables and prevalence of CMP as the dependent variable for all 10 anatomical pain locations separately and the overall variable of CMP. PRs and 95\% confidence intervals were estimated. Differences in PRs between men and women were quantified by testing interaction (Altman and Bland, 2003).

\section{Results}

Compared to men, women in this study were on average younger (25-46 years), lower educated, less often had a paid job, more often never smoker, they more often had a low BMI $\left(<25 \mathrm{~kg} / \mathrm{m}^{3}\right)$, more often reported moderate to high physical activity (compared to low physical activity), and they showed higher levels of pain catastrophizing (Table 1).

Positive and statistically significant associations were found between female sex and CMP in the neck, shoulder, higher back, wrist/hand, hip, foot, and the overall variable of CMP. Slightly positive, but not statistically significant, associations were found for the elbow, knee and ankle. No sex differences were found for the lower back (Table 2). 
Table 2.

Association between sex and chronic musculoskeletal pain, adjusting for other potential risk factors of musculoskeletal pain, $n=2087$

\begin{tabular}{|c|c|c|c|c|c|c|c|c|c|c|c|}
\hline & Neck & Shoulder & $\begin{array}{l}\text { Higher } \\
\text { back }\end{array}$ & Elbow & Wrist/hand & $\begin{array}{l}\text { Lower } \\
\text { back }\end{array}$ & Hip & Knee & Ankle & Foot & $\begin{array}{l}\text { Any } \\
\text { location }\end{array}$ \\
\hline Sex & $1.72(1.36-2.18)$ & $1.41(1.23-1.75)$ & $2.07(1.43-3.01)$ & $1.31(0.91-1.88)$ & $1.83(1.35-2.48)$ & $0.99(0.82-1.19)$ & $2.29(1.55-3.40)$ & $1.16(0.89-1.51)$ & $1.42(0.87-2.31)$ & $1.59(1.05-2.41)$ & $1.18(1.04-1.35)$ \\
\hline Sex + age & $1.77(1.40-2.25)$ & $1.44(1.16-1.80)$ & $2.10(1.45-3.05)$ & $1.38(0.96-1.98)$ & $1.89(1.39-2.56)$ & $1.00(0.83-1.21)$ & $2.40(1.62-3.57)$ & $1.19(0.91-1.55)$ & $1.47(0.90-2.39)$ & $1.65(1.09-2.50)$ & $1.20(1.05-1.37)$ \\
\hline Sex + educ. level & $1.67(1.32-2.12)$ & $1.36(1.09-1.70)$ & $2.01(1.39-2.93)$ & $1.25(0.86-1.79)$ & $1.79(1.32-2.43)$ & $0.96(0.80-1.16)$ & $2.25(1.52-3.35)$ & $1.14(0.88-1.49)$ & $1.37(0.84-2.24)$ & $1.55(1.02-2.35)$ & $1.17(1.03-1.33)$ \\
\hline Sex + working & $1.43(1.11-1.84)$ & $1.18(0.93-1.50)$ & $1.70(1.14-2.52)$ & $1.18(0.80-1.75)$ & $1.55(1.12-2.14)$ & $0.89(0.73-1.09)$ & $1.80(1.24-2.61)$ & $0.94(0.71-1.26)$ & $1.01(0.60-1.70)$ & $1.26(0.81-1.96)$ & $1.11(0.96-1.27)$ \\
\hline$\%$ change $\mathrm{PR}^{\mathrm{a}}$ & 17 & 16 & 18 & 10 & 15 & 10 & 21 & 19 & 29 & 21 & 6 \\
\hline Sex (paid job) & $1.78(1.28-2.48)$ & $1.26(0.93-1.72)$ & $2.46(1.44-4.20)$ & $1.19(0.73-1.95)$ & $1.60(1.05-2.43)$ & $0.89(0.69-1.16)$ & $2.23(1.28-3.90)$ & $0.92(0.62-1.35)$ & $1.20(0.55-2.59)$ & $1.69(0.92-3.10)$ & $1.14(0.96-1.36)$ \\
\hline Sex (no paid job) & $1.08(0.76-1.55)$ & $1.08(0.76-1.54)$ & $1.09(0.64-1.86)$ & $1.17(0.62-2.19)$ & $1.47(0.89-2.44)$ & $0.90(0.65-1.23)$ & $1.45(0.80-2.63)$ & $0.98(0.64-1.49)$ & $0.88(0.45-1.74)$ & $0.92(0.50-1.67)$ & $1.05(0.83-1.32)$ \\
\hline Sex + smoking & $1.76(1.39-2.22)$ & $1.43(1.15-1.79)$ & $2.11(1.45-3.06)$ & $1.34(0.93-1.93)$ & $1.85(1.37-2.52)$ & $1.01(0.83-1.21)$ & $2.37(1.60-3.52)$ & $1.18(0.90-1.53)$ & $1.46(0.90-2.38)$ & $1.58(1.04-2.39)$ & $1.20(1.05-1.36)$ \\
\hline Sex + overweight & $1.80(1.42-2.28)$ & $1.48(1.18-1.84)$ & $2.21(1.52-3.22)$ & $1.40(0.97-2.01)$ & $1.94(1.43-2.63)$ & $1.01(0.84-1.22)$ & $2.45(1.65-3.64)$ & $1.28(0.98-1.66)$ & $1.59(0.98-2.60)$ & $1.72(1.13-2.61)$ & $1.21(1.06-1.38)$ \\
\hline Sex + physical act. & $1.73(1.37-2.19)$ & $1.41(1.13-1.76)$ & $2.10(1.44-3.04)$ & $1.31(0.91-1.89)$ & $1.82(1.34-2.47)$ & $1.00(0.83-1.20)$ & $2.34(1.57-3.47)$ & $1.16(0.89-1.51)$ & $1.44(0.88-2.35)$ & $1.62(1.07-2.46)$ & $1.19(1.04-1.35)$ \\
\hline Sex + pain catastr. & $1.63(1.28-2.06)$ & $1.32(1.06-1.65)$ & $1.90(1.31-2.76)$ & $1.25(0.87-1.80)$ & $1.75(1.29-2.38)$ & $0.95(0.79-1.14)$ & $2.12(1.42-3.15)$ & $1.13(0.86-1.47)$ & $1.30(0.80-2.13)$ & $1.47(0.97-2.23)$ & $1.15(1.01-1.31)$ \\
\hline$\%$ change $\mathrm{PR}^{\mathrm{b}}$ & 5 & 6 & 8 & 5 & 4 & 4 & 7 & 3 & 8 & 8 & 3 \\
\hline Sex + all var. ${ }^{d}$ & $1.53(1.18-1.98)$ & $1.26(0.99-1.61)$ & $1.73(1.15-2.59)$ & $1.36(0.91-2.04)$ & $1.74(1.24-2.42)$ & $0.91(0.74-1.12)$ & $2.31(1.51-3.52)$ & $1.14(0.85-1.53)$ & $1.28(0.72-2.10)$ & $1.38(0.88-2.18)$ & $1.15(1.00-1.33)$ \\
\hline$\%$ change $\mathrm{PR}^{\mathrm{c}}$ & 11 & 11 & 16 & -4 & 5 & 8 & -1 & 2 & 10 & 13 & 3 \\
\hline
\end{tabular}

Cox regression is used and Prevalence Ratios (PR) are presented with their 95\% Confidence Intervals (CI).

Percentage change of crude PR after adjusting for a working status; ${ }^{b}$ pain catastrophizing; ${ }^{c}$ all variables; ${ }^{d}$ Age, educational level, working status, smoking status, overweight, physical inactivity, pain catastrophizing. 
For all 10 pain locations and the overall variable of CMP, sex differences - if present - could not be explained by age, educational level, smoking status, overweight, physical activity, and pain catastrophizing (Table 2). When adding work status to the model, the crude PR for the association between female sex and CMP decreased by $10 \%$ or more for all pain locations (Table 2 ). Stratifying PRs by work status revealed that work status was an effect modifier of the association between sex and CMP; there were no sex differences in CMP in the population without a paid job. In the population with a paid job, sex differences remained statistically significant for the neck, the higher back, the wrist/hand, and the hip (Table 2).

Table 3 presents the (multivariately adjusted) sex-stratified associations between potential risk factors for CMP and CMP for all 10 anatomical pain locations separately and the overall variable of CMP. The main results will be summarized here. Older age was generally associated with higher prevalence of CMP in both men and women. However, for the knee and foot, associations with older age were positive for women but not for men (interaction tested: $p=0.04$ (knee); 0.02 (foot)). Low or medium educational level (compared to high) tended to be associated with higher prevalence of CMP, but generally associations were not statistically significant. Opposite associations were found for the knee (women). Not having a paid job was generally associated with higher prevalence of CMP, but more strongly in men than in women. Although most associations were not statistically significant, past or current smoking (compared to never smoking) tended to be associated with higher prevalence of CMP in both men and women. Associations tended to be stronger in men than in women (interaction tested (knee): $p=0.05)$. Overweight (BMI $>25 \mathrm{~kg} / \mathrm{m}^{3}$ ) was generally associated with higher prevalence of CMP, but associations were stronger and statistically significant for women only. Interaction with sex was tested statistically significant for the lower back $(p=0.04)$, knee $(p=0.01)$, and overall variable of CMP $(p=0.02)$. Although most associations were weak, low physical activity tended to be associated with CMP in women, while moderate to high physical activity tended to be associated with CMP in men. Interaction with sex was tested statistically significant for the wrist/hand only $(p=0.04)$. A higher level of pain catastrophizing was generally associated with higher prevalence of CMP in both men and women. However, for the higher back and elbow, associations were stronger in men than in women (interaction tested: $p=0.04 / 0.02$ (higher back); $p=0.05 / 0.08$ (elbow)).

Table 3.

Multivariate Cox regression models on the association between several patient characteristics (independent variables) and chronic musculoskeletal pain in different anatomical locations (dependent variable), stratified by sex; associations are expressed as a Prevalence Ratios (PR) $)^{1,2}$

\section{Discussion}

The results can be summarized as follows. First, sex differences in CMP could not be explained by a different distribution of age, educational level, smoking status, overweight, physical activity, and pain catastrophizing. Work status did explain part of the sex differences in CMP (more women than men have no paid job and not having a paid job is associated with CMP). Second, the impact of potential risk factors of CMP differed between men and women but was not the same for different pain locations. Risk factors with a sex-specific association with CMP 
were: overweight (all pain locations) and older age (lower extremities) - women only - and pain catastrophizing (upper extremities) - stronger for men than for women.

Work status explained part of the sex differences in CMP. This is (statistically) due to the fact that more women than men have no paid job and not having a paid job is associated with CMP. The association between not having a paid job and CMP is likely to be due to two effects: good health - i.e. absence of CMP enables men and women to have a paid job (selection effect) and having a paid job promotes health - i.e. absence of CMP - (health effect) (Fokkema, 2002). This health effect can be explained by the fact that a paid job offers social contacts, professional challenges, a sense of responsibility, self-respect en selfworth as well as an income of one's own (Fokkema, 2002). No sex differences were found in the population without a paid job while in the population with a paid job, women reported more CMP than men. One explanation is that women are more likely without a paid job for reasons like child care or household tasks, while men are more likely without a paid job because of work-disablement for example due to CMP. This explanation is supported by data from the present study population without a paid job: in women, $8 \%$ was unemployed, $18 \%$ was work disabled and $74 \%$ was housekeeper, volunteer, student/scholar, or on early retirement; in men, these percentages were, respectively, $13 \%, 49 \%$ and $38 \%$ (data not shown). Yet another explanation may be that men are more prone to quit working due to CMP than women due to differences in the nature of the CMP, differences in work demands, or psychosocial differences between men and women. In sum, work status seems to play a complex modifying and/or mediating role in the association between sex and CMP. Our data are not fit to examine the above-proposed mechanisms of the associations in detail; this requires further study in other data-sets.

For all pain locations, overweight (BMI $>25 \mathrm{~kg} / \mathrm{m}^{2}$ ) was associated more strongly with CMP in women than in men. When examining the literature, evidence supporting or rejecting these findings is scarce. A systematic review on the association between body weight and low back pain (Leboeuf-Yde, 2000) shows that $32 \%$ of 65 studies reported a positive association between body weight and low back pain, but no evidence was found for a stronger association in women compared to men (Leboeuf-Yde, 2000). In another study, although statistically significant in both sexes, women showed slightly stronger associations between obesity and MP in five anatomical locations (neck, back, hip, knee, and ankle) (Peltonen et al., 2003). A general population study among men and women older than 72 years showed that overweight (BMI $>27 \mathrm{~kg} / \mathrm{m}^{3}$ ) was associated with widespread pain in women only (Leveille et al., 2005). In another general population study, overweight was stronger associated with general chronic health problems in women than in men (Denton et al., 2004). More research is needed to examine the association between overweight and CMP separately for men and women for different pain locations. If overweight is a risk factor of CMP in women but not, or less strong, in men, this may be important information for sex-specific management of CMP.

For most pain locations in the upper part of the body, the prevalence of CMP increased with increasing age in both men and women, while for the lower extremities older age was associated with CMP in women but not in men. Other studies in the general population (Webb et al., 2003) and in working populations (de Zwart et al., 1997 and Guo et al., 2004) found that increasing age was associated with MP, also in the lower extremities (de Zwart et al., 1997), in both men and women. Although age is not a risk factor that can be targeted in sex- 
specific prevention of CMP, the possible interaction with sex may help to uncover sex-related underlying pathology in future studies.

As expected, higher pain catastrophizing was generally associated with higher prevalence of CMP in both men and women. However, for the higher back and elbow, stronger associations were found for men compared to women, suggesting that for CMP in the upper extremities, the influence of pain catastrophizing on development and maintenance of CMP may be stronger in men than in women. This hypothesis is supported by previous studies on general pain. Despite lower pain ratings, men were found to have more anxiety related to pain than women (Frot et al., 2004). In addition, in patients with chronic pain, the associations between dimensions of pain and various pain-related emotions (depression, anxiety, frustration, anger and fear) were generally stronger in men than in women (Riley et al., 2001). Furthermore, one study showed that pain coping instructions are more beneficial with respect to pain experience in men than in women (Keogh and Herdenfeldt, 2002).

Educational level, physical activity and smoking status were not strongly associated with CMP in this study and no strong sex differences in associations were observed. Several studies examined the association between smoking and low back pain (Leboeuf-Yde et al., 1998, Feldman et al., 1999 and Leboeuf-Yde, 1999) and one with widespread MP (Andersson et al., 1998) and although not strong, there is substantial evidence for a positive association, but no sex differences were found. In our study, the association between smoking and CMP in the shoulder, elbow, and knee (although weak) was stronger for men than for women. This may be explained by the assumption that men had a higher number of packyears of smoking than women. This favors the existence of an association between smoking and CMP but does not suggest a sex-specific vulnerability to smoking.

Besides general risk factors for CMP applicable to both men and women, sexspecific risk factors, like hormonal differences, may also play a role in the higher vulnerability of women to develop CMP. In a cross sectional analysis among 11,428 adult women from the Dutch general population, irregular or prolonged menstrual cycle, hysterectomy, (past) pregnancy, young maternal age at first birth, duration of oral contraceptive use, and use of estrogens during menopause were associated with chronic low back pain and/or chronic upper extremity pain (Wijnhoven et al., in press). Furthermore, we are aware that there may be additional risk factors for CMP that were not included in this study like sex differences in social and psychological factors like sex role beliefs, mood, and pain-related expectancies. Finally, many laboratory studies of humans have described sex differences in sensitivity to noxious stimuli, suggesting that biological mechanisms may underlie sex differences in pain in general (Wiesenfeld-Hallin, 2005).

Some general remarks should be made when interpreting the study results. First, self-report assessment of data may have resulted in misclassification of data due to recall errors. Since this is expected equally for all respondents (i.e. those with and those without CMP), it is called non-differential misclassification. This usually results in an underestimation of associations (Grimes and Schulz, 2002). Second, the cross-sectional nature of this study does not allow disentanglement of cause and effect. For example, overweight may be either the cause or the result of CMP or both. The third remark concerns potential non-response bias due to relatively high non-response. Based on the general characteristics from the population register, respondents and non-respondents did not differ (Picavet and Schouten, 2003). Respondents excluded due to missing data did not differ from the included 
study population either (Table 1 ). In addition, the validity of our results is supported by similar associations between female sex and (chronic) musculoskeletal pain found in other general population studies (Andersson et al., 1993, Natvig et al., 1995, Urwin et al., 1998 and Bergman et al., 2001) and working population studies (de Zwart et al., 2001, Eriksen, 2003 and Guo et al., 2004).

In conclusion, sex differences in CMP in general population aged 25-65 could not be explained by a different distribution of general risk factors for CMP, but some risk factors had a different impact on CMP in men and women, supporting the vulnerability model. Future research towards sex-specific identification of risk factors for CMP is warranted. Eventually this may lead to sex-specific prevention and management of CMP.

\section{References}

Altman and Bland, 2003 D.G. Altman and J.M. Bland, Interaction revisited: the difference between two estimates, Br Med J 326 (2003), p. 219.

Andersson et al., 1993 H.I. Andersson, G. Ejlertsson, I. Leden and C. Rosenberg, Chronic pain in a geographically defined general population: studies of differences in age, gender, social class, and pain localization, Clin J Pain 9 (1993), pp. 174-182.

Andersson et al., $1998 \mathrm{H}$. Andersson, G. Ejlertsson and I. Leden, Widespread musculoskeletal chronic pain associated with smoking. An epidemiological study in a general rural population, Scand J Rehabil Med 30 (1998), pp. 185-191.

Barros and Hirakata, 2003 A.J. Barros and V.N. Hirakata, Alternatives for logistic regression in crosssectional studies: an empirical comparison of models that directly estimate the prevalence ratio, $B M C$ Med Res Methodol 3 (2003), p. 21.

Bergman et al., 2001 S. Bergman, P. Herrstrom, K. Hogstrom, I.F. Petersson, B. Svensson and L.T. Jacobsson, Chronic musculoskeletal pain, prevalence rates, and sociodemographic associations in a Swedish population study, J Rheumatol 28 (2001), pp. 1369-1377.

Denton et al., 2004 M. Denton, S. Prus and V. Walters, Gender differences in health: a Canadian study of the psychosocial, structural and behavioural determinants of health, Soc Sci Med $\mathbf{5 8}$ (2004), pp. 2585-2600.

de Zwart et al., 2001 B.C. de Zwart, M.H. Frings-Dresen and A. Kilbom, Gender differences in upper extremity musculoskeletal complaints in the working population, Int Arch Occup Environ Health $\mathbf{7 4}$ (2001), pp. 21-30.

de Zwart et al., 1997 B.C.H. de Zwart, J.P.J. Broersen, M.H.W. Frings-Dresen and F.J.H. van Dijk, Musculoskeletal complaints in the Netherlands in relation to age, gender and physically demanding work, Int Arch Occup Environ Health 70 (1997), pp. 352-360.

Eriksen, 2003 W. Eriksen, The prevalence of musculoskeletal pain in Norwegian nurses' aides, Int Arch Occup Environ Health 76 (2003), pp. 625-630.

Feldman et al., 1999 D.E. Feldman, M. Rossignol, I. Shrier and L. Abenhaim, Smoking. A risk factor for development of low back pain in adolescents, Spine 24 (1999), pp. 2492-2496.

Felson et al., 2000 D.T. Felson, R.C. Lawrence, P.A. Dieppe, R. Hirsch, C.G. Helmick and J.M. Jordan et al., Osteoarthritis: new insights. Part 1: the disease and its risk factors, Ann Intern Med 133 (2000), pp. 635-646.

Fokkema, 2002 T. Fokkema, Combining a job and children: contrasting the health of married and divorced women in the Netherlands?, Soc Sci Med 54 (2002), pp. 741-752. 
Frot et al., 2004 M. Frot, J.S. Feine and M.C. Bushnell, Sex differences in pain perception and anxiety. A psychophysical study with topical capsaicin, Pain 108 (2004), pp. 230-236.

Gran, 2003 J.T. Gran, The epidemiology of chronic generalized musculoskeletal pain, Best Pract Res Clin Rheumatol 17 (2003), pp. 547-561.

Grimes and Schulz, 2002 D.A. Grimes and K.F. Schulz, Bias and causal associations in observational research, Lancet 359 (2002), pp. 248-252.

Guo et al., 2004 H.R. Guo, Y.C. Chang, W.Y. Yeh, C.W. Chen and Y.L. Guo, Prevalence of musculoskeletal disorder among workers in Taiwan: a nationwide study, J Occup Health 46 (2004), pp. 26-36.

Hildebrandt et al., 2000 V.H. Hildebrandt, P.M. Bongers, J. Dul, F.J. van Dijk and H.C. Kemper, The relationship between leisure time, physical activities and musculoskeletal symptoms and disability in worker populations, Int Arch Occup Environ Health 73 (2000), pp. 507-518.

Keogh and Herdenfeldt, 2002 E. Keogh and M. Herdenfeldt, Gender, coping and the perception of pain, Pain 97 (2002), pp. 195-201.

Leboeuf-Yde et al., 1998 C. Leboeuf-Yde, K.O. Kyvik and N.H. Bruun, Low back pain and lifestyle. Part I: Smoking. Information from a population-based sample of 29,424 twins, Spine 23 (1998), pp. 2207-2213 discussion 2214.

Leboeuf-Yde, 1999 C. Leboeuf-Yde, Smoking and low back pain. A systematic literature review of 41 journal articles reporting 47 epidemiologic studies, Spine 24 (1999), pp. 1463-1470.

Leboeuf-Yde, 2000 C. Leboeuf-Yde, Body weight and low back pain. A systematic literature review of 56 journal articles reporting on 65 epidemiologic studies, Spine 25 (2000), pp. 226-237.

Leino-Arjas et al., 1998 P. Leino-Arjas, K. Hanninen and P. Puska, Socioeconomic variation in back and joint pain in Finland, Eur J Epidemiol 14 (1998), pp. 79-87.

Leveille et al., 2005 S.G. Leveille, Y. Zhang, W. McMullen, M. Kelley-Hayes and D.T. Felson, Sex differences in musculoskeletal pain in older adults, Pain 116 (2005), pp. 332-338.

Miranda et al., 2001 H. Miranda, E. Viikari-Juntura, R. Martikainen, E.P. Takala and H. Riihimaki, A prospective study of work related factors and physical exercise as predictors of shoulder pain, Occup Environ Med 58 (2001), pp. 528-534.

Natvig et al., 1995 B. Natvig, I. Nessioy, D. Bruusgaard and O. Rutle, Musculoskeletal symptoms in a local community, Eur J Gen Practice 1 (1995), pp. 25-28.

Oliveria et al., 1999 S.A. Oliveria, D.T. Felson, P.A. Cirillo, J.I. Reed and A.M. Walker, Body weight, body mass index, and incident symptomatic osteoarthritis of the hand, hip, and knee, Epidemiology 10 (1999), pp. 161-166.

Palmer, 2003 K.T. Palmer, Regional musculoskeletal conditions: pain in the forearm, wrist and hand, Best Pract Res Clin Rheumatol 17 (2003), pp. 113-135.

Peltonen et al., 2003 M. Peltonen, A.K. Lindroos and J.S. Torgerson, Musculoskeletal pain in the obese: a comparison with a general population and long-term changes after conventional and surgical obesity treatment, Pain 104 (2003), pp. 549-557.

Picavet et al., 2002 H.S. Picavet, J.W. Vlaeyen and J.S. Schouten, Pain catastrophizing and kinesiophobia: predictors of chronic low back pain, Am J Epidemiol 156 (2002), pp. 1028-1034.

Picavet and Schouten, 2003 H.S. Picavet and J.S. Schouten, Musculoskeletal pain in the Netherlands: prevalences, consequences and risk groups, the DMC(3)-study, Pain 102 (2003), pp. 167-178.

Punnet and Herbert, 2000 L. Punnet and R. Herbert, Work-related musculoskeletal disorders: is there a gender differential, and if so, what does it mean?. In: M.B. Goldman and M.C. Hatch, Editors, Women and health, Academic Press, San Diego, CA (2000), pp. 474-492. 
Riley et al., 2001 J.L. Riley, M.E. Robinson, J.B. Wade, C.D. Myers and D.D. Price, Sex differences in negative emotional responses to chronic pain, J Pain 2 (2001), pp. 354-359. Abstract | PDF (59 K)

Strazdins and Bammer, 2004 L. Strazdins and G. Bammer, Women, work and musculoskeletal health, Soc Sci Med 58 (2004), pp. 997-1005.

Sullivan et al., 1995 H.J.L. Sullivan, S.R. Bishop and J. Pivik, The pain catestrophizing Scale : development and validation, Psychol Assess 7 (1995), pp. 524-532.

Urwin et al., 1998 M. Urwin, D. Symmons and T. Allison et al., Estimating the burden of musculoskeletal disorders in the community: the comparative prevalence of symptoms at different anatomical sites, and the relation to social deprivation, Ann Rheum Dis 57 (1998), pp. 649-655.

van der Windt et al., 2000 D.A. van der Windt, E. Thomas, D.P. Pope, A.F. de Winter, G.J. Macfarlane, L.M. Bouter and A.J. Silman, Occupational risk factors for shoulder pain: a systematic review, Occup Environ Med 57 (2000), pp. 433-442.

van Tulder et al., 2002 M. van Tulder, B. Koes and C. Bombardier, Low back pain, Best Pract Res Clin Rheumatol 16 (2002), pp. 761-775.

Vlaeyen and Linton, 2000 J.W. Vlaeyen and S.J. Linton, Fear-avoidance and its consequences in chronic musculoskeletal pain: a state of the art, Pain 85 (2000), pp. 317-332.

Webb et al., 2003 R. Webb, T. Brammah, M. Lunt, M. Urwin, T. Allison and D. Symmons, Prevalence and predictors of intense, chronic, and disabling neck and back pain in the UK general population, Spine 28 (2003), pp. 1195-1202.

Wendel-Vos et al., 2003 G.C. Wendel-Vos, A.J. Schuit, W.H. Saris and D. Kromhout, Reproducibility and relative validity of the short questionnaire to assess health-enhancing physical activity, $J$ Clin Epidemiol 56 (2003), pp. 1163-1169.

Wiesenfeld-Hallin, 2005 Z. Wiesenfeld-Hallin, Sex differences in pain perception, Gend Med 2 (2005), pp. $137-145$.

Wijnhoven et al., in press Wijnhoven HA, de Vet HC, Picavet HS. Prevalence of musculoskeletal pain is systematically higher in women than in men. Clin J Pain 2006; in press.

Wijnhoven et al., in press Wijnhoven HA, de Vet HC, Smit HA, Picavet HS. Hormonal and reproductive factors are associated with chronic low back pain and chronic upper extremity pain in women - the MORGEN study. Spine 2006;31:in press. 